\title{
Tsunamigenic potential of outer-rise normal faults at the Middle America trench in Central America
}

\author{
José A. Álvarez-Gómez ～，Omar Q. Gutiérrez Gutiérrez ，IIñigo Aniel-Quiroga ， M. González
}

Keywords:

Tsunami

Middle America trench

Central America

Outer-rise earthquakes

Subduction

Earthquake scaling-relation

\begin{abstract}
A B S T R A C T
The Middle America trench is formed by the subduction of the Cocos and Rivera plates under the Caribbean and North American plates. The subduction interface presents low coupling in Central America showing its seismicity a high frequency of outer-rise normal fault earthquakes. These outer-rise earthquakes are generated on the inherited structures of the seafloor-spreading fabric during the subducting plate bending. We analyze focal mechanism data in combination with the available structural data of the outer-rise normal faults in order to constrain the rupture characteristics of the outer-rise normal earthquakes. A new empirical scaling relationship is developed to define earthquake magnitudes from normal fault dimensions in the outer-rise context. We numerically model the tsunami wave propagation due to the worst outer-rise tsunamigenic source in the area to estimate its damaging potential. Wave elevations higher than $2 \mathrm{~m}$ are common at the coast in front of the fault extent, with maximum wave elevations of $8 \mathrm{~m}$. The capability of these faults to generate ocean-wide tsunamis is low, however, they can produce significant tsunamis locally.
\end{abstract}

\section{Introduction}

Although less frequent than the subduction thrust earthquakes, the outer-rise normal earthquakes have generated destructive tsunamis in the past (e.g. Fujii and Satake, 2008; Gusman et al, 2009; Satake et al, 1992). As was pointed out by Satake et al. (1992): “This has important implications to future hazard assessment, particularly from tsunamis, since most hypothetical tsunamis have been assumed to be generated from underthrusting events associated with subduction"; specially in those subducton zones where the tsunamigenic underthrusting events are not usual.

The Middle America trench is formed by the subduction of the Cocos and Rivera plates under the Caribbean and North American plates (Fig. 1). This trench can be divided into two main segments: the Mexican and the Central American; where the upper plate is respectively the North American and the Caribbean. The tectonics on both segments is markedly different due to the motion of the respective upper plates (Fig. 1). While the North American plate is moving towards the trench, the Caribbean plate is moving in the opposite direction, away from the trench (Burbach et al., 1984). This fact makes the coupling on both segments of the subduction different and hence the seismic behavior too. The Mexican segment is coupled while the Central American is uncoupled (Álvarez-Gómez et al., 2008; Guzmán-Speziale and Gómez-González, 2006; Lyon-Caen et al., 2006; Pacheco et al., 1993). One of the characteristics of the low coupled subductions is the high frequency of normal intraslab earthquakes in the upper part of the slab, particularly the outer-rise earthquakes (Christensen and Ruff, 1988); due to the efficient transmission of the slab pull forces towards the upper part of the subducting plate (Conrad et al., 2004). These intraslab earthquakes are probably the largest events in uncoupled subduction zones, rather than the underthrusting events (Satake et al., 1992).

The bathymetry of the Middle America Trench offshore of Central America shows a very clear pattem of outer-rise normal faulting (Ranero et al., 2003, 2005) and the frequency of outer-rise normal earthquakes is high compared to other subduction zones worldwide, comparable to the activity of other low-coupled subductions like Marianas or Sunda.

Considering the history of tsunamis in Central America, the local sources are those that present the greatest threat. Fig. 2 shows the epicenters of the sources of tsunamis in Central America according to the work of Fernández (2002). To these we added the recent events of Chile in 2010 and Japan in 2011, that also were recorded in Central America. From the distant sources only the event of 1957 in the Aleutian Islands generated notable damage. This event caused victims in El Salvador causing major damage to the port of Acajutla. Of the tsunamis that have hit the Pacific coast of Central America only 4 have been generated by distant sources (including the two recent tsunamis of Chile and Japan) versus 30 local events (considering also local the event that occurred in 1906 off the coast of Colombia) 7 of which were damaging (Fig. 2). Local tsunamis associated with the subduction zone have 


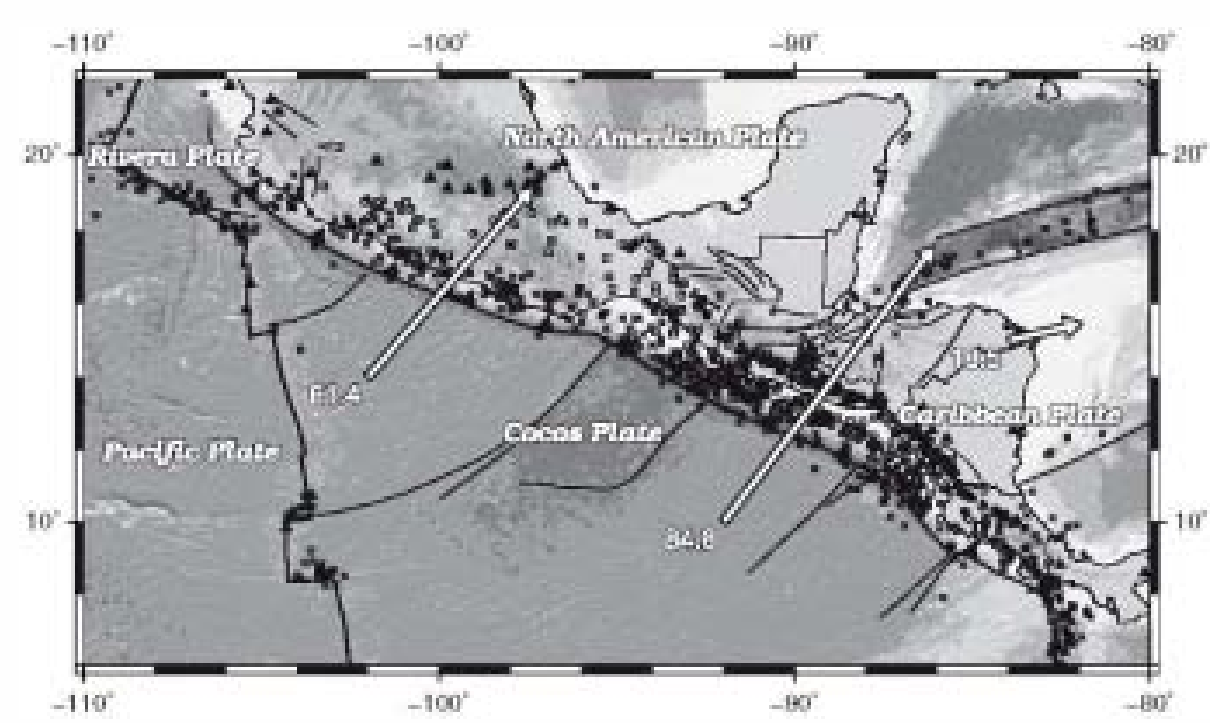

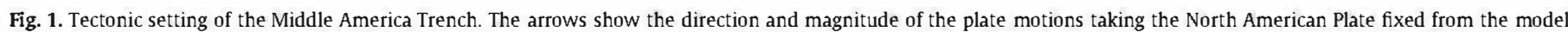

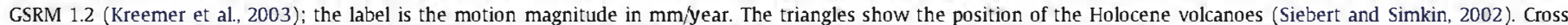
symbols represent the shallow seismicity $(<50 \mathrm{~km})$ and squares the rest of the seismic Global CMT catalog (Ekström et al., 2012).

been classically attributed to earthquakes due to subduction of the Cocos plate under the Caribbean plate (Fernández et al., 2000) although no details of the focal mechanism exist. The outer-rise normal earthquakes are common in Central America and may play an important role as local sources of desuctive tsunamis.

In this work we analyze available structural and seismic data in order to characterize the potential outer-rise normal seismic tsunamigenic sources. In addition we numerically model the tsunami wave propagation due to the worst case outer-rise tsunamigenic source in the area.

\section{Analysis of the seismicity}

In order to constrain the orientation parameters of the potential outer-rise tsunamigenic sources we have used the Global CMT seismic catalog (Ekström et al., 2012) to analyze the focal mechanism characteristics of the outer-rise seismicity. This catalog has been filtered in order to select the outer-rise normal earthquakes. The geographical

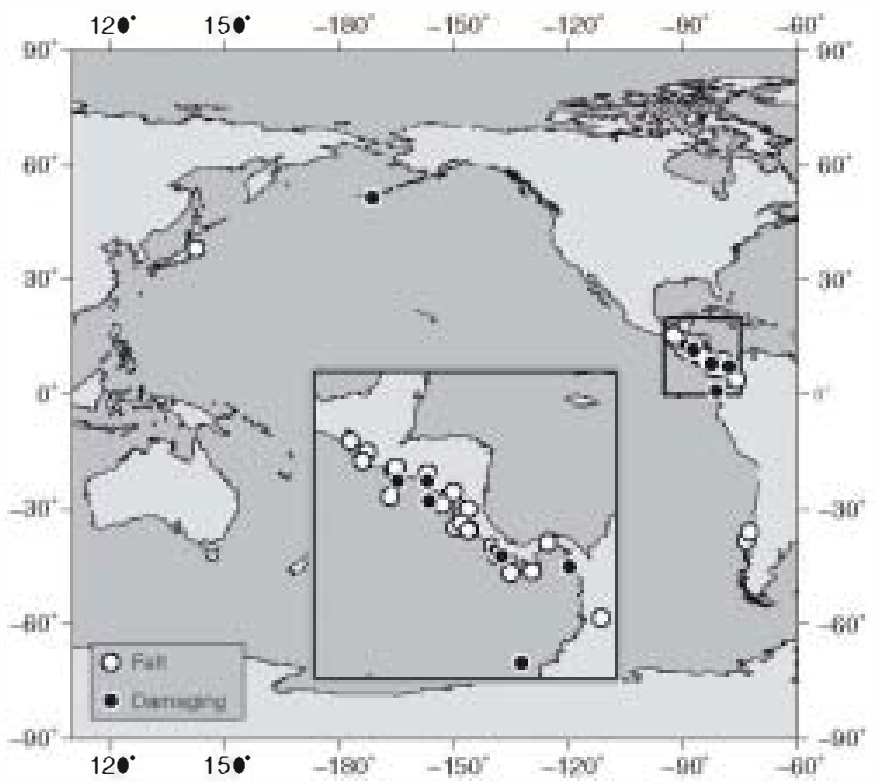

Fig. 2. Tsunami catalog ofthe pacific coast of Central America. The map shows the epiœnters of the events. White circles: nondestructive tsunamis. Black circles: damaging tsunamis. The data is from Femández (2002) except for the recent events of Chile 2010 and Japan 2011. extension of the seismic data is shown in Fig. 3 and comprises earthquakes since 1976 with magnitudes $M_{W}$ between 4.5 and 8.0.

The catalog is composed of 1871 events that have been classified by the rupture type using the classification diagram shown in Fig. 3 (Âlvarez Gómez, 2009). 440 events of the catalog are normal or normal-directional, 695 are strike-slip or strike-slip with dip-slip component and 736 are reverse or reverse-directional.

The outer-rise events have been selected applying a distance filter from the trench and a depth threshold: a band of $100 \mathrm{~km}$ from the trench and a maximum depth of $50 \mathrm{~km}$ (Fig. 4). The maximum depth of $50 \mathrm{~km}$ is an initial assumption, but below it will be shown that a maximum depth of $30 \mathrm{~km}$ for the occurrence of these outer-rise normal earthquakes is a good estimation, in accordance with previous works (Chapple and Forsyth, 1979; Lefeldt and Grevemeyer, 2008; Spence, 1986). From the 440 normal events of the catalog 31 are located near the trench and shallower than $30 \mathrm{~km}$ deep.

We used the program ZMAP (Wiemer, 2001) in order to obtain the b-value of the Gutenberg-Richter law for these events (Fig. 5). The value obtained is 1.02 , close to the value of 1 , proposed as universal for the law, specially on small earthquakes (Andrews, 1980; Hanks, 1979; Olsson, 1999). The range of magnitudes for the calculation of the law and the number of events is limited, although the range of variation of the b-value is not large.

From the b-value obtained we can estimate return periods for this kind of outer-rise earthquakes. The annual rate for an earthquake with magnitude $\mathrm{Mi}$ or greater is defined by the equation:

$\lambda_{M i}=\exp \alpha-\boldsymbol{\beta M i}$,

where $\alpha=a \times \ln (10)$ and $\beta=b \times \ln (10) ; a$ and $b$ are the parameters of the Gutenberg-Richter law. The return period is defined as the inverse of the annual rate of exceedance: $T=1 \lambda_{M i}$. In Table 1 the return periods for the exceedance of several magnitudes are shown. The values of the return period range between 2 years for a magnitude 5.5 earthquake and 560 years for a magnitude 7.9 earthquake (the maximum magnitude estimated from the geology in this work as shown below).

Table 1

Return periods for outer-rise normal earthquakes in the Middle America Trench. See explanation in the text.

\begin{tabular}{lllcccc}
\hline Magnitude $\left(M_{W}\right)$ & 5.5 & 6.0 & 6.5 & 7.0 & 7.5 & 7.9 \\
Return period (years) & 2.00 & 6.46 & 20.89 & 67.61 & 218.77 & 559.76 \\
\hline
\end{tabular}




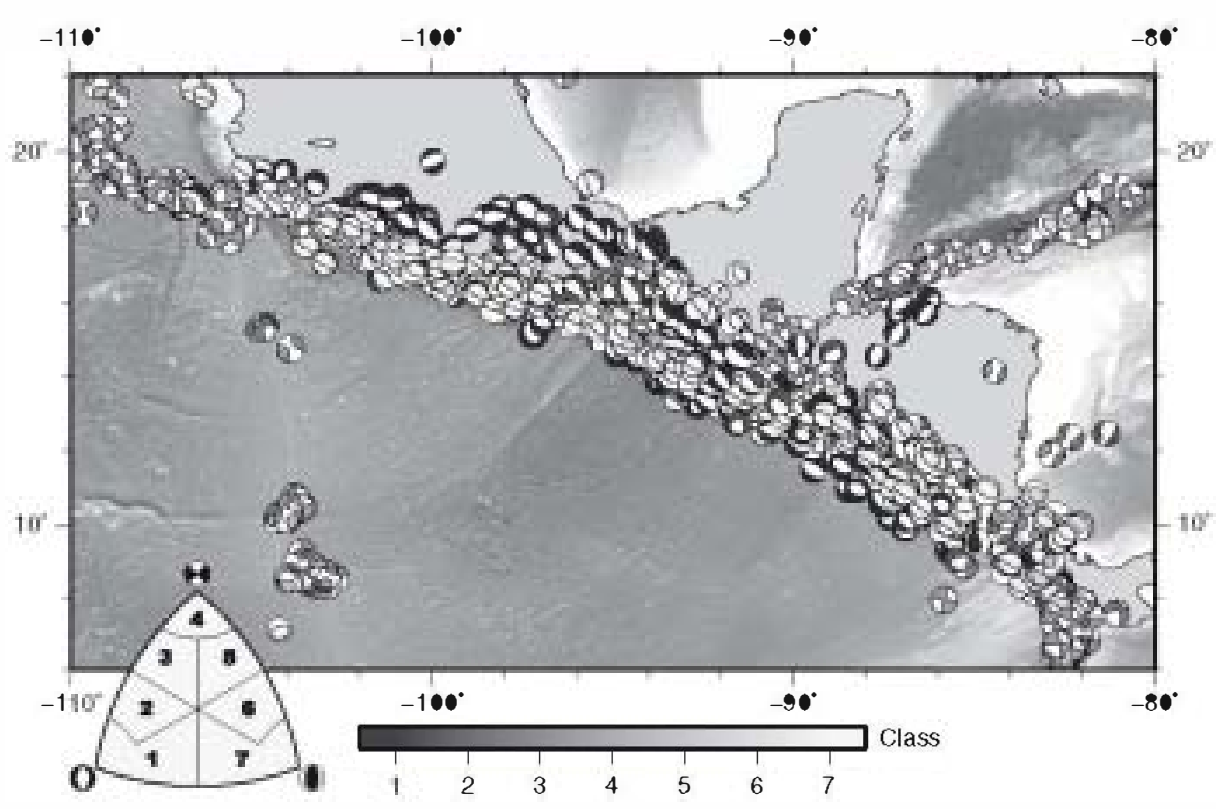

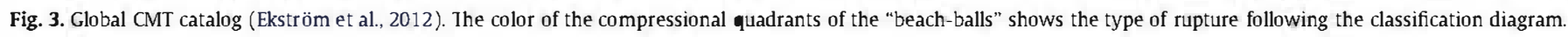

From the analysis of the focal mechanism of the events we can obtain key parameters for the study of the seismic source: hypocentral depth, magnitude, strike, dip and rake. We show the variation of these parameters along the trench in Fig. 6, the profile situation is shown in Fig. 4. The parameters have been obtained from the Seismic Moment Tensor of the Global CMT catalog (Ekström et al., 2012) using an Octave code based partially in the Gasperini and Vannucci (2003) FORTRAN algorithms (Álvarez Gómez, 2009).

\subsection{Depth}

This parameter is crucial not only because the capacity of the earthquake to generate surface deformation depends on the depth, but also for its maximum depth of rupture, which will be a key factor in determining the maximum magnitude of the event. In Fig. 6a the hypocentral depth variation of the normal fault events in the subduction in the first $50 \mathrm{~km}$ is shown. The two distinct populations of events are clearly visible. The shallow events $(<30 \mathrm{~km})$ are the potential causes of tsunamis and have been marked in dark gray on all graphs. The deeper normal earthquakes $(>30 \mathrm{~km})$ are intraplate events on the subducting plate, whose capacity to lead directly to surface deformation, and therefore to generate tsunamis, is very low and are not considered in this work. Although the depth is used to be the worst constrained parameter of the focal mechanism the two subgroups are well defined. As mentioned earlier, shallow normal fault events are especially common in the trench off the coast of Guatemala, El Salvador and Nicaragua (Fig. 4).

\subsection{Magnitude}

While obtaining the expected maximum magnitude of an earthquake based on the seismic catalog is complex to do, forcing us to make assumptions and simplifications, the spatial distribution of magnitudes depending on the tectonic context and rupture depth

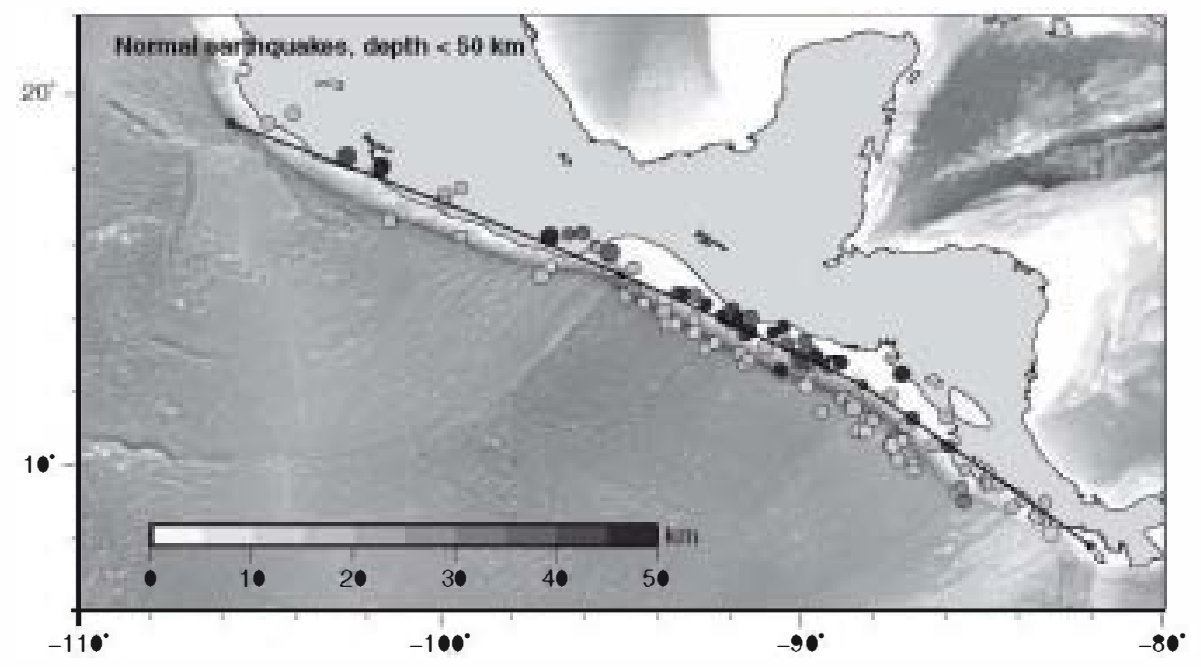

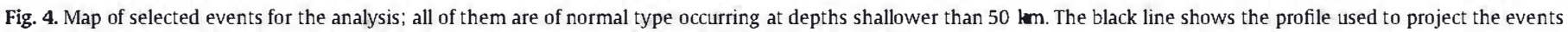
for Fig. 6, the empty circles show the transition between segments marked with dashed lines in Fig. 6. 


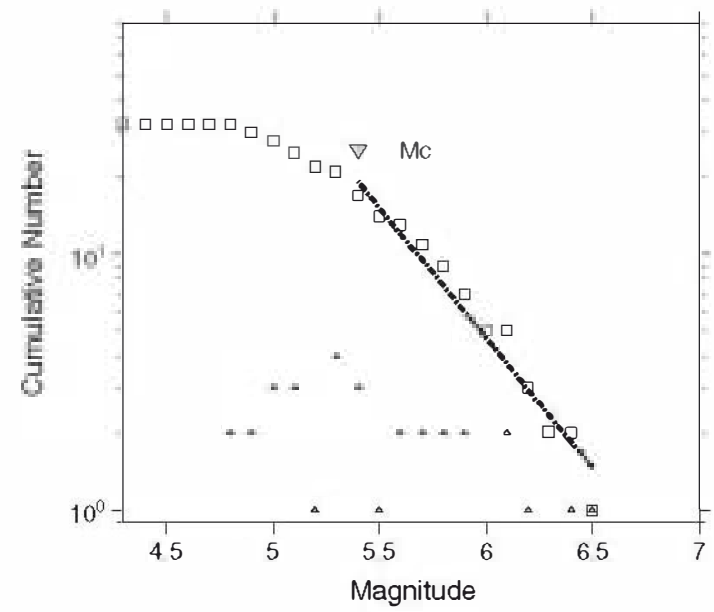

Maximum Likelihøed Estimate Uncertainties by boetstrapping

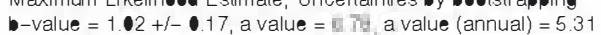
Magnitude of Completeness $=5.4+1-63$

Fig. 5. Frequency vs. magnitude Gutenberg-Richter relation for outer-rise seismicity in the study area. The events selected are of normal type and produced at depths shallower than $30 \mathrm{~km}$. Upward triangles show the frequency for each magnitude bin $(0.1)$, squares show the cumulative frequency, the downward filled triangle shows the Magnitude of completeness (Mc). The dashed line is the projection of the best fitting maximum likelihood estimate of the Gutenberg-Richter law.

can help us to establish a zoning or dependence of the magnitude on the earthquake location. In Fig. 6b can be seen that the maximum magnitudes recorded in recent decades for the shallow events (dark gray) are around $M_{W}$ 6.3-6.5. There is no clear variation on the magnitudes of the shallow events along the trench, showing a relative homogeneity of the outer-rise normal faulting seismicity in Central America from the Gulf of Tehuantepec to Costa Rica.

\subsection{Strike}

This parameter determines the orientation of the bulge of deformation generated by the earthquake and the main direction of propagation of the tsunami energy. Fig. $6 \mathrm{c}$ shows two distinct populations of directions: one with values of $N 120^{\circ} \mathrm{E}$ and the other with values of $\mathrm{N} 300^{\circ} \mathrm{E}$. These directions correspond to the stike of the pattern of oceanic crust generation in the Eastern Pacific Ridge; the different value is just due to the opposite dip directions of the nodal planes in the focal mechanism (giving the $180^{\circ}$ difference). These faults can be observed in the subducting slab on the outer side of the trench (Ranero et al., 2003, 2005). The strikes are fairly constant throughout the trench, with the exception of the westernmost part of the Mexican subduction, and slight variations in Costa Rica.

\subsection{Dip}

Depending on the dip of the fault plane, the deformation caused by the earthquake will be transmitted to a greater or lesser extent to the surface. This parameter is critical when estimating the variables used in the numerical models. Again two distinct populations are shown, although in this case the variation along the subduction is quite evident (Fig. 6d). In the Mexican trench both families of dips remain approximately constant at $30^{\circ}$ and $60^{\circ}$; while passing the Gulf of Tehuantepec both families take values of about $40^{\circ}$ and $55^{\circ}$ respectively. This approaching of the values indicates a maximum stress $\sigma_{1}$ verticalization, which could be explained by a more efficient transmission of the tensile stresses generated by slab pull on the subducted plate. In Costa Rica the dip populations tend to separate again to values of $20^{\circ}$ and $70^{\circ}$.

\subsection{Rake}

The pitch of the slip vector on the fault plane determines how much of the deformation generated by the earthquake is transmitted in vertical and horizontal components. This parameter, along with the dip and the magnitude of the displacement in the rupture, is decisive in the amount of strain that is transmitted as vertical deformation to the seafloor. In the case of rake (Fig. 6e) two distinct populations cannot be seen. Although with some small variations, the population tends to present a mean rake of $-90^{\circ}$, with the majority of the population between $-60^{\circ}$ and $-120^{\circ}$. Although slight, a tendency to decrease in the value of rake from the Gulf of Tehuantepec to Costa Rica exists. The values go from $-85^{\circ}$ in Guatemala to $-95^{\circ}$ in Nicaragua and Costa Rica, that is, from events with a very slight left-lateral component to a very slight right-lateral component.

As a conclusion of this analysis we can define some parameters confidently in the Central American trench from the Tehuantepec Ridge to the subduction of the Cocos Ridge in Costa Rica. The parameters of the nodal planes of the outer-rise normal earthquakes are fairly constant and coherent.

\section{Analysis of the tectonic structures}

Ranero et al. (2005) published a map of outer-rise structures of the Middle America Trench from Guatemala to Costa Rica (Fig. 7). Although they did not cover all the trench from the Tehuantepec Ridge, the amount of data can be considered representative of the structural pattern of the Cocos plate. We have analyzed these structures in order to constrain some geometric parameters of the ruptures.

It is generally accepted that the outer-rise earthquakes take place on faults generated initially in the mid ocean ridges (Masson, 1991). The bending of the subducting slab under the upper plate and the tensile stresses of the slab-pull reactivate these faults, giving rise to these characteristic earthquakes on this tectonic context. In low coupled subduction zones a better transmission of the tensile stresses toward the trench exists (Christensen and Ruff, 1988; Conrad et al., 2004), which makes these normal fault earthquakes more frequent than in the rest of the subduction zones.

We digitized the structures mapped by Ranero et al. (2005) and we analyzed the frequency of fault directions representing them in a rose diagram (Fig. 7). We have found strike values ranging from $\mathrm{N} 300^{\circ} \mathrm{E}$ to $\mathrm{N} 330^{\circ} \mathrm{E}$ in the trench from Guatemala to Nicaragua. These directions are in the same range of those described in the nodal planes of the focal mechanisms of the outer-rise shallow earthquakes (Fig. 6). We can infer that these events are therefore generated by these faults as has been proposed previously (Ranero et al., 2005).

In the trench off Costa Rica there is a change in the directions of faults from $\mathrm{N} 300^{\circ} \mathrm{E}-\mathrm{N} 330^{\circ} \mathrm{E}$ to $\mathrm{N} 250^{\circ} \mathrm{E}-\mathrm{N} 280^{\circ} \mathrm{E}$ directions. This is due to a change in the pattern of fracturing. East of the Nicoya Peninsula appears the subduction of the Cocos ridge, with roughness and morphologycal characteristics very different to that in the oceanic crust generated at the Pacific Ridge.

If the faults mapped by Ranero et al. (2005) are responsible for the outer-rise seismicity, then they are potential outer-rise tsunamigenic sources of the subduction in Central America. As we have seen, the maximum magnitude recorded in these outer-rise events in Central America, is $M_{W} 6.5$. However, in the last century, several such events with magnitudes near 8 or higher have occurred in the world, some of them resulting in major tsunamis (Table 2) (Beavan et al., 2010; 


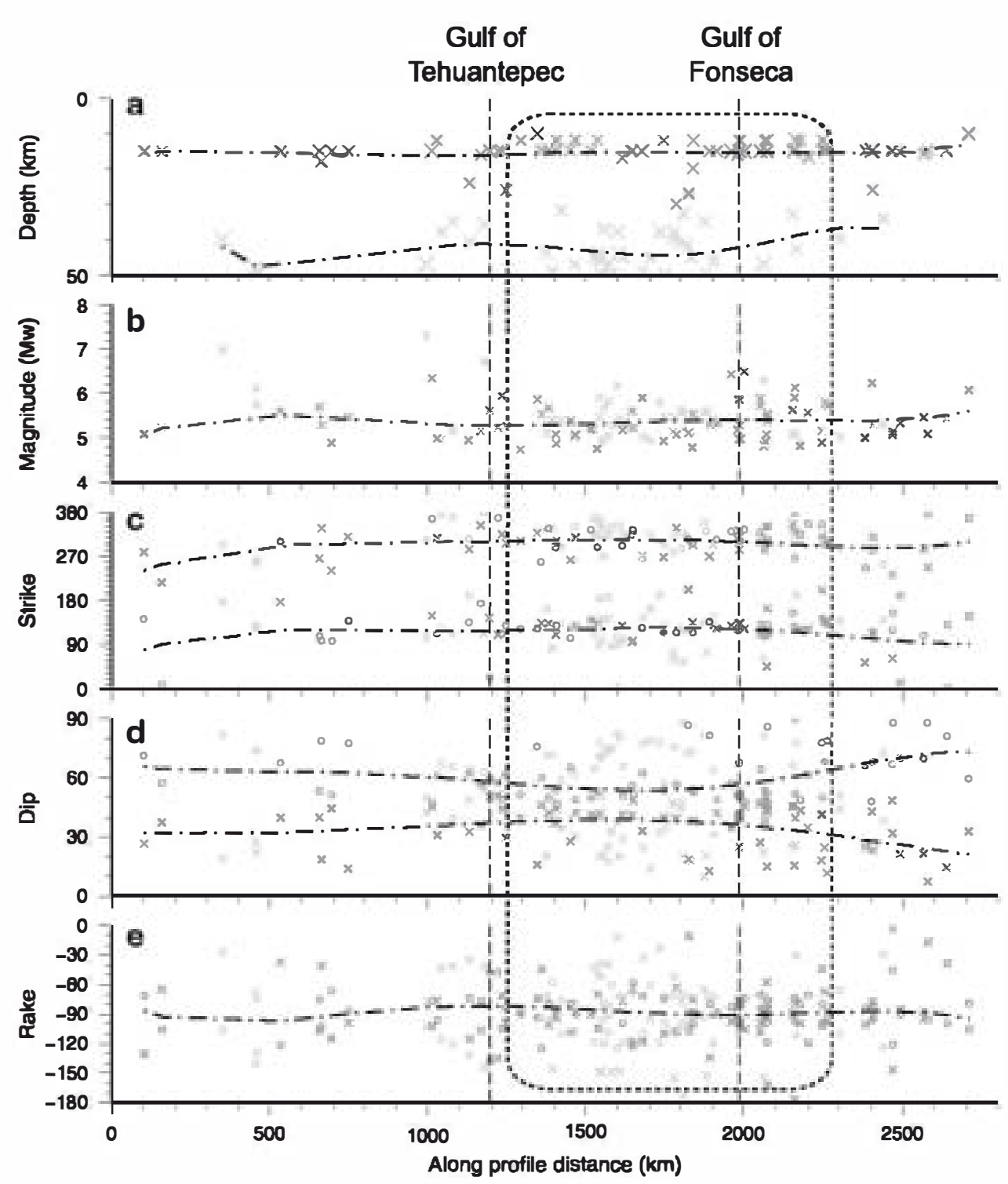

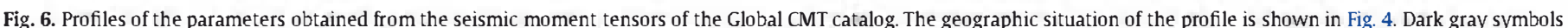

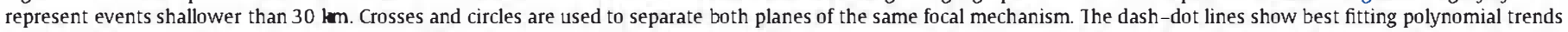

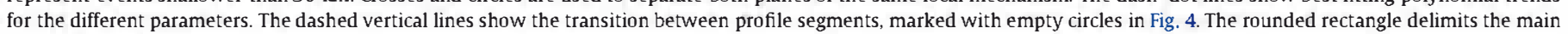
area of the study.

Gusman et al., 2009; Kirby et al., 2008; Satake et al., 1992; Tanioka et al., 2008).

Usually the way to obtain geological maximum magnitudes is by means of empirical scaling relations. To estimate the maximum earthquake these equations relate the magnitude of the potential earthquake with known dimensions of the fault. Such relationships have been studied for earthquakes in continental crust (e.g. Stirling et al., 2002; Wells and Coppersmith, 1994) and are the basis for many seismotectonic studies and seismic hazard analyses and, unfortunately, even in studies of tsunamis generated in subduction zones or oceanic crust. The variability of the relations is high, not only between different rheological behavior crusts, but also between different regions and tectonic settings (Dowrick and Rhoades, 2004; Strasser et al., 2010).

The problem with these outer-rise faults is the lack of data on the characteristics of the ruptures. In Table 2 is presented a series of cases in which rupture features have been estimated for major outer-rise events. These parameters have been obtained from inverted teleseismic data and/or distribution of aftershocks (Abe, 1972; Beck and Christensen, 1991; Fromm et al., 2006; Fujii and
Satake, 2008; Kanamori, 1971; Kirby et al., 2008; Lynnes and Lay, 1988; Satake et al., 1992; Spence, 1986; Yoshida et al., 1992) or observations of tsunami waves (Gusman et al., 2009; Tanioka et al., 2008).

To estimate appropriate magnitudes for the faults in this tectonic context we have developed a specific scale relation for these outerrise events. This relation is based on parameters obtained from the literature (Table 2). The scarcity of data from these events is compensated by the selection of truly representative events of this type of process. In Fig. 8 the results obtained for the relationships magnitudelength and magnitude-area of rupture are shown.

To select the most appropriate scale relation, assuming that anyone of the two relations presented is sufficiently representative (Table 3), we obtained the magnitudes $M_{W}$ from mapped fault lengths and areas (based on these lengths and assuming a rupture area with $\mathrm{L} / \mathrm{W}=1$ until the maximum seismogenic depth is reached). We have set the maximum seismogenic depth at $30 \mathrm{~km}$, according to the analysis of the seismicity and to the compiled bibliographic data (Table 2). Similarly, the dip selected as characteristic for these ruptures is $45^{\circ}$, consistent with both bibliographic data and focal mechanisms data. 


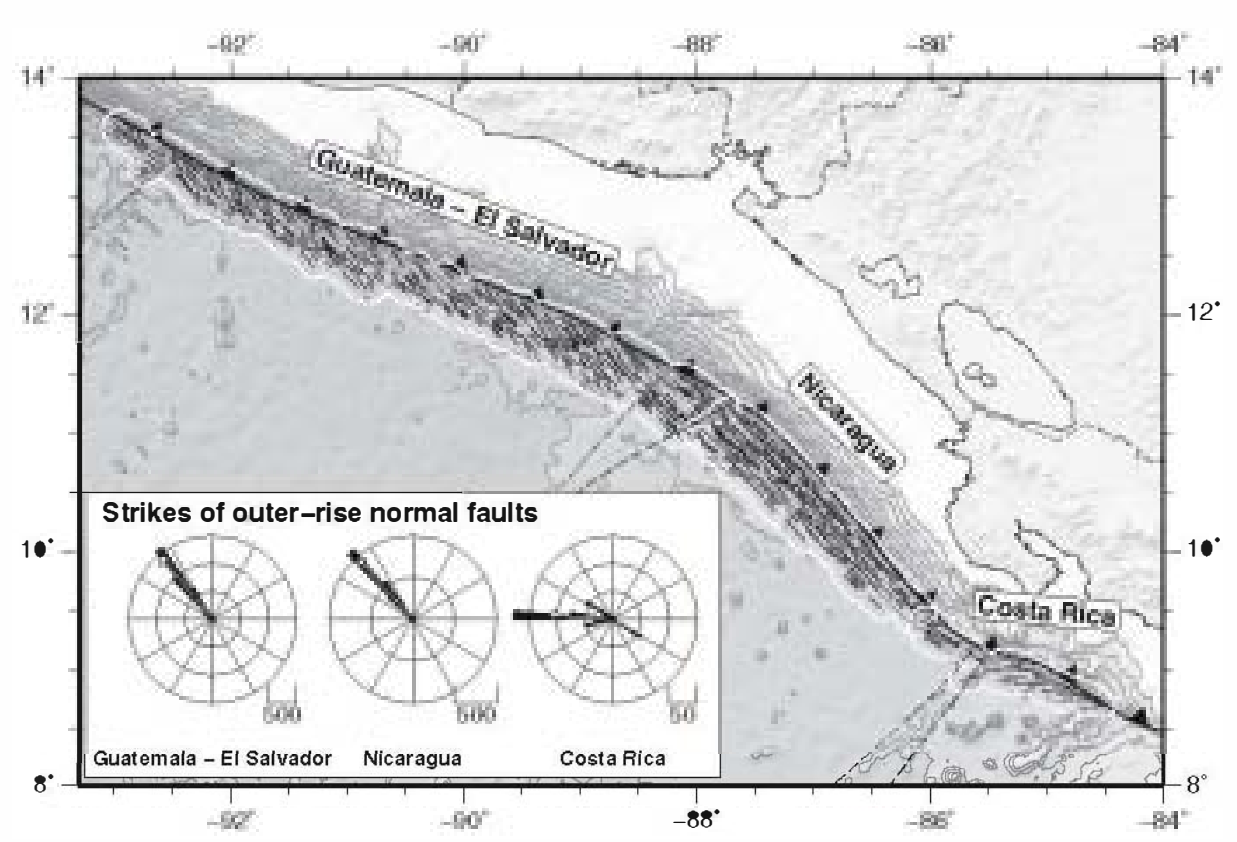

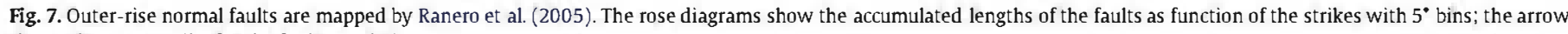
shows the mean strike for the fault population.

We studied the frequency distribution of magnitudes for comparison with the Gutenberg-Richter law obtained from the seismicity (Fig. 5). Fig. 9 shows these laws for all normal faults of the trench. The area scaling relation (Fig. 9a) yields a b-value of 1 of the GutenbergRichter law, while for the length scaling relation (Fig. 9b) this value is considerably higher.

The b-values of the Gutenberg-Richter law are very similar in the outer-rise seismicity and on the outer-rise normal faults with the magnitude obtained with the $M_{W}$-Area relation. According to this similarity we use this relationship to obtain the dimension parameters needed to characterize the tsunamigenic ruptures in the outer-rise normal faults.

In Fig. 10 are shown those faults mapped by Ranero et al. (2005) whose magnitudes are greater than $M_{W} 6.5$. Among these are a series of faults capable of generating earthquakes of magnitudes greater than 7.5 $M_{W}$. The worst case of these sources is mapped off the coast of Nicaragua, with an estimated maximum magnitude $M_{W}$ 7.9. From the geometry obtained from the study of seismicity and mapping, and the earthquake magnitude from the scaling relationship, we have parametrized the worst case for its use as tsunami source (Table 4).

\section{Tsunami propagation model}

To estimate the tsunamigenic potential of the outer-rise normal faults in Central America we made propagation numerical models using the worst case of those obtained. The worst case source is a fault with a length of $85 \mathrm{~km}$ located off the coast of Nicaragua, for which we calculated a potential magnitude $M_{W} 7.9$ (Fig. 10).

In order to study the hazard associated to these faults in Central America we computed wave propagations along the Middle American trench using the worst case characteristics. 12 propagations of the worst case were made, from the Tehuantepec gulf, in Mexico, to Costa Rica (Supplementary data).

We used the numerical model of propagation $\mathrm{C} 3$ (Olabarrieta et al., 2011). This model uses a finite difference method for propagation at sea (adapting the model COMCOT (Liu et al., 1995)) and finite

Table 2

Rupture parameters of the compiled outer-rise great events.

\begin{tabular}{|c|c|c|c|c|c|c|c|c|c|c|}
\hline \multirow[t]{2}{*}{ Id. } & Date & Place & $M_{W}$ & \multirow{2}{*}{$\frac{\text { Length }}{\mathrm{km}}$} & \multirow{2}{*}{$\frac{\text { Width }}{\mathrm{km}}$} & \multirow{2}{*}{$\frac{\text { Bottom }}{\mathrm{km}}$} & \multirow{2}{*}{$\frac{\text { Dip }}{}$} & \multirow{2}{*}{$\frac{\text { Slip }}{\mathrm{m}}$} & \multirow{2}{*}{$\frac{\text { Rigidity }}{\mathrm{Nm}^{-2}}$} & \multirow[t]{2}{*}{ Reference } \\
\hline & $\mathrm{dd} / \mathrm{mm} / \mathrm{yyyy}$ & & & & & & & & & \\
\hline a & 03/02/1933 & Sanriku & 8.4 & 185 & 100 & 70 & 45 & 3.3 & - & Kanamori (1971) \\
\hline b & $03 / 02 / 1933$ & Sanriku & 8.4 & 220 & 35 & 25 & 45 & 8 & $7.0 \times 10^{1 \bullet}$ & Kirby et al. (2008) \\
\hline $\mathrm{c}$ & $30 / 03 / 1965$ & Rat Island & 7.2 & 50 & 80 & 60 & 50 & 1.2 & $7.0 \times 10^{1 \bullet}$ & Abe $(1972)$ \\
\hline $\mathrm{d}$ & $30 / 03 / 1965$ & Rat Island & 7.2 & 50 & 40 & 30 & 50 & 6 & $5.0 \times 10^{1 \bullet}$ & Beck and Christensen (1991) \\
\hline e & $19 / 08 / 1977$ & Sunda & 8.2 & 200 & 70 & 40 & 45 & 3 & $6.4 \times 10^{1 \bullet}$ & Gusman et al. (2009) \\
\hline f & $19 / 08 / 1977$ & Sunda & 8.2 & 200 & 25 & 29 & 45 & 9 & $4.0 \times 10^{10}$ & Spence (1986), Lynnes and Lay (1988) \\
\hline$g$ & $04 / 05 / 1990$ & Mariana & 7.3 & 40 & 25 & 29 & 48 & 3.4 & $4.0 \times 10^{10}$ & Satake et al. (1992) \\
\hline $\mathrm{h}$ & $04 / 05 / 1990$ & Mariana & 7.3 & 70 & 40 & 40 & 48 & 1.5 & $4.0 \times 10^{1 \bullet}$ & Satake et al. (1992) \\
\hline $\mathrm{i}$ & $04 / 05 / 1990$ & Mariana & 7.3 & 70 & 40 & - & 48 & - & - & Yoshida et al. (1992) \\
\hline $\mathrm{j}$ & $04 / 09 / 2001$ & Juan Fernandez Ridge & 6.7 & 70 & 26 & 30 & 51 & 1 & $4.0 \times 10^{1 \bullet}$ & Fromm et al. (2006) \\
\hline $\mathrm{k}$ & $13 / 01 / 2007$ & Kuril & 7.9 & 120 & 40 & 35 & 45 & 1.9 & $5.0 \times 10^{10}$ & Fujii and Satake (2008) \\
\hline I & $13 / 01 / 2007$ & Kuril & 8.0 & 130 & 30 & - & 37 & 6.4 & $4.0 \times 10^{10}$ & Tanioka et al. (2008) \\
\hline
\end{tabular}



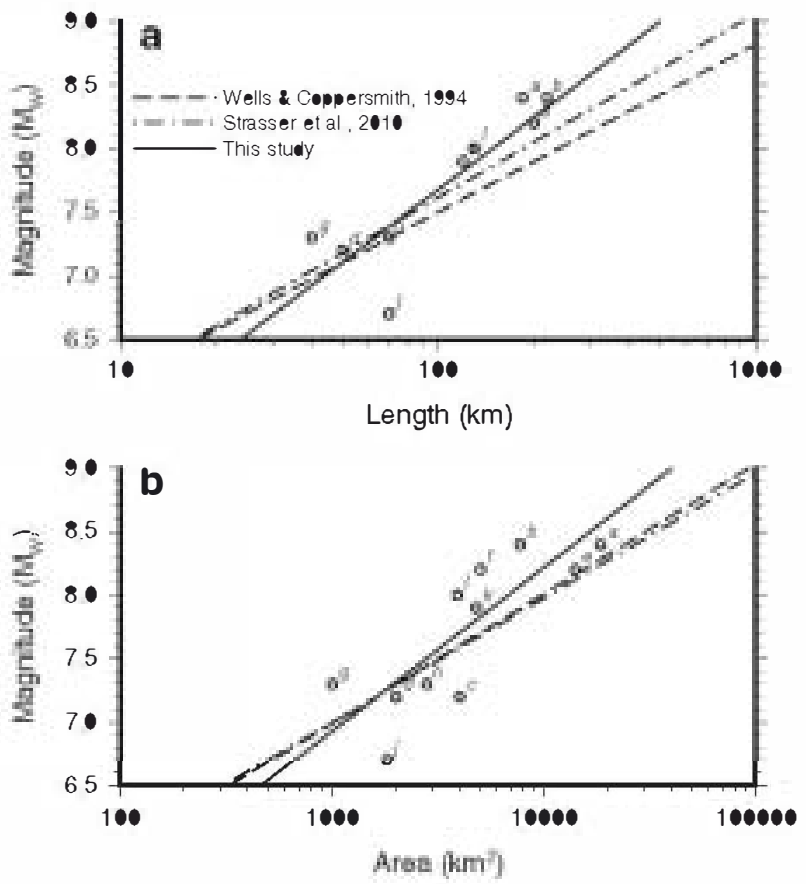

Fig. 8. Scaling relations obtained from compiled big outer-rise earthquakes compared with previous relations for continental crust normal earthquakes (Wells and Coppersmith, 1994) and subduction intraslab earthquakes (Strasser et al., 2010). Black circles and text show the events compiled; see Table 2 for further details. Relations presented: a) Magnitude $\mathrm{M}_{\mathcal{W}}$-Iength; b) Magnitude $\mathrm{M}_{\mathcal{W}}$-Area.

volumes for the flooding model (George, 2008). For this study we used only propagation at sea.

Like other codes, C3 models the tsunami propagation from the source zone to a given coastal region and its consequent run-up using the NonLinear Shallow Water (NLSW) equations. In a Cartesian coordinate system these equations can be expressed as:

Mass conservation equation:

$\frac{\partial \zeta}{\partial t}+\frac{\partial P}{\partial x}+\frac{\partial Q}{\partial y}=0$

Momentum conservation equations:

$$
\begin{aligned}
& \frac{\partial P}{\partial t}+\frac{\partial P^{2}}{\partial x}+\frac{\partial P Q}{\partial y}+g H \frac{\partial \zeta}{\partial x}+\tau_{x} H-f Q=0 \\
& \frac{\partial P}{\partial t}+\frac{\partial P Q}{\partial x}+\frac{\partial Q^{2}}{\partial y}+g H \frac{\partial \zeta}{\partial y}+\tau_{y} H-f P=0
\end{aligned}
$$

Where $\zeta$ is the free surface elevation above mean sea level; $x$ and $y$ represent the longitude and latitude of the earth; $\tau_{x}$ and $\tau_{y}$ are the bottom shear stress in $x$ axis (pointing to the east) and $y$ axis (pointing to the north); $P$ and $Q$ stand for the volume fluxes $(P=H u$ and $Q=H v$ with $u$ and $v$ being the depth-averaged velocities in the longitude and latitude direction); $H$ is the total water depth

Table 3

Scaling relations obtained from compiled big outer-rise earthquakes (Table 2). Sc and $\mathrm{Sm}$ are the standard errors of $\mathrm{c}$ and $\mathrm{m}$ respectively. $\mathrm{r}^{2}$ is the determination coefficient and $\mathrm{N}$ the number of data used in the regression.

\begin{tabular}{lllllll}
\hline & $\mathrm{c}$ & $\mathrm{Sc}$ & $\mathrm{m}$ & $\mathrm{Sm}$ & $\mathrm{r}^{2}$ & $\mathrm{~N}$ \\
\hline$M_{W}=c+m \log _{1 \mathbf{0}} L$ & 3.89 & 0.63 & 1.89 & 0.31 & 0.78 & 12 \\
$M_{W}=c+m \log _{10} A$ & 3.06 & 1.05 & 1.28 & 0.29 & 0.66 & 12 \\
\hline
\end{tabular}

$(H=h+\zeta)$ with $h$ being the water depth; $\mathcal{f}$ represents the Coriolis parameter; and $g$ is the acceleration due to gravity.

We used the topobathymetric database GEBCO_08 (GEBCO, 2008) with a cell size of 30". The initial surface deformation was calculated using the parameters shown in Table 4 with the equations of Okada (1985).

In Fig. 11 the result of the propagation numerical model of the worst case outer-rise fault is shown as maximum elevation of the wave and tsunami travel time. At first glance you can see how most of the wave energy is concentrated in front of the fault extent, while propagation to the rest of the ocean basin is almost negligible. The maximum elevations generated at the Nicaraguan coast exceed two meters in general, the maximum obtained being about $8 \mathrm{~m}$. Moreover the travel time data shows how a wave generated in this type of local sources will take approximately 45 min to reach the coast in front of its location. However the source modeled in this particular work, because of its proximity to Costa Rica, shows travel times much shorter to the coast of the Nicoya peninsula, which would be affected by the waves in just over $20 \mathrm{~min}$ from its generation. This difference in travel time is because the speed of propagation is proportional to the depth. Thus, along the subduction trench, with depths close to $6000 \mathrm{~m}$, the propagation velocity is considerably larger than in the continental shelf, with depths of less than $200 \mathrm{~m}$.

In Fig. 12 we show the maximum wave elevations (MWE) along the Central American coast at the bathymetric contour of $10 \mathrm{~m}$ depth for each of the modeled sources (the correspondent maps are shown in the supplementary data available online). Some common features can be extracted. Independently on the location of the source the maximum wave elevation is greater than $2 \mathrm{~m}$, which can produce damaging inundations. Most of the source locations can produce wave elevations greater than $5 \mathrm{~m}$. The affected areas span several hundreds of kilometers along the coast; from approximately $200 \mathrm{~km}$ (source OR-3) to around $500 \mathrm{~km}$ (source OR-1).

If we analyze the distribution of elevations contributed from all the source locations we can determine the coast areas which are the most exposed to the tsunami hazard. In Fig. 12 we show a graph displaying the mean and median maximum wave elevations from all the source locations. Some peaks and troughs are evident, and are common features in the maximum wave elevation results of diff erent source locations. These features are marked with letters in Fig. 12. Some of the peaks and troughs seem to be related to submarine canyons on the continental slope (B, C, D, E, F, G, H?) while others are related to coastal morphology, like the area of the Gulf of Fonseca (I) or the Gulf of Papagayo in Costa Rica (K).

\section{Discussion}

Ifin low coupled subduction zones large interplate earthquakes are not likely (Christensen and Ruff, 1988; Conrad et al., 2004), we might think that these are areas with low tsunami risk. However, in these areas normal fault events are relatively common and are a potential source of tsunamis (Satake et al., 1992). Moreover, in subduction zones with low interplate coupling also tsunamigenic earthquakes can occur in the form of slow earthquakes or tsunami-earthquakes rupturing the accretionary wedge (Ide et al., 1993; Pelayo and Wiens, 1992; Tanioka and Sataka, 1996).

The subduction in Central America is low coupled (Álvarez-Gómez et al., 2008; Guzmán-Speziale and Gómez-González, 2006; Lyon-Caen et al., 2006; Pacheco et al., 1993) and shows a high frequency of outer-rise normal earthquakes compared with the surrounding areas, as shown above. We should consider these outer-rise faults as probable sources of tsunamis in the future and perhaps as a potential cause of local tsunamis in the past, typically attributed to the subduction interface, similar to the 1992 Nicaragua tsunami earthquake (Ide et al., 1993; Imamura et al., 1993; Satake, 1994). 


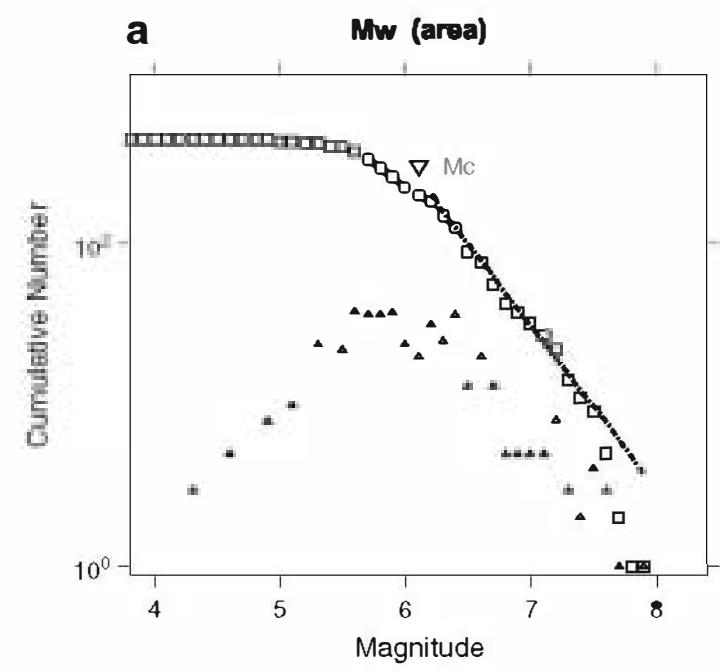

Maximum Likelihøod Estimate, Uncertainties boetstrapping - -value $=1+\delta-6.8$ a value $=8.52$, a value $($ annual $)=\operatorname{lnt}$ Magnitude of Dambialensan $=6.1+1-\bullet .3$ b Mw (length)

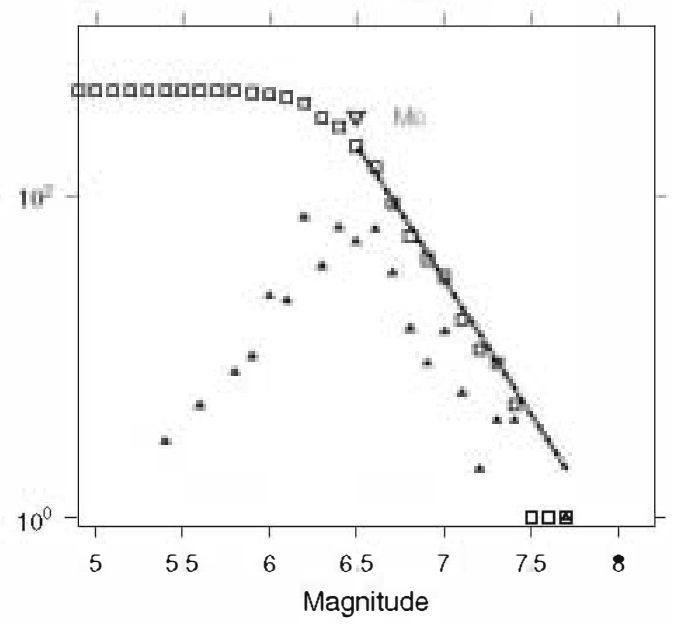

Maximum Likeliheod Estimate, Uncertainties by botstrapping -value $=1.66+\delta-24$, a value $=13.1$, a value (annual $)=\operatorname{lnt}$ Magnitude of Completeness $=6.5+1-\bullet 11$

Fig. 9. Gutenberg-Richter relation for all the outer-rise normal faults. Magnitudes obtained with a) the $\mathrm{M}_{\mathcal{W}}$-Area scaling relation, and b) the $\mathrm{M}_{\mathcal{W}}$-Length scaling relation.

The most damaging tsunamis in Central America have been produced by local sources. The most recent records from which data are available, from the twentieth century onwards, show three major destructive events on the Pacific coast of Central America (Fernández and Alvarado-Delgado, 2005). These events are the tsunami of El Salvador, 1902, the Aleutian tsunami of 1957 and the tsunami in Nicaragua in 1992.

The Aleutian tsunami, the only destructive of the far events, produced damage mainly in the area of Acajutla in El Salvador (Fernández et al., 2000). This area has a clear tendency to amplification of damage (Fernández et al., 2004), with a relative peak in the modeled wave elevations as shown in Fig. 12 (marked with the letter $G)$. However, other areas that also have these peaks did not suffer the same damage with the same event. There may be other local effects of coastal amplification in the Acajutla area, or perhaps different characteristics of the Aleutian tsunami wave are the responsible. Detailed propagation and flooding models of this tsunami would be required to clarify this.

Of the local tsunamis, the most damaging was the Nicaraguan 1992 event. This tsunami was caused by a reverse fault type in the subduction interface. It was a tsunami earthquake that ruptured probably the shallowest section of the subduction interface (Satake, 1994; Velasco et al., 1994). Its effects were very destructive in Nicaragua, where wave heights reached more than $9 \mathrm{~m}$, but the tsunami was recorded along the Salvadorian and Costa Rican pacific coast of Central America too (Baptista et al., 1993; Fernández and Alvarado-Delgado, 2005; Fernández et al., 2004; Satake et al., 1993).

The tsunami of 1902 was more local, causing damage mainly in the area from the south of Guatemala (E, F in Fig. 12) to the cost of

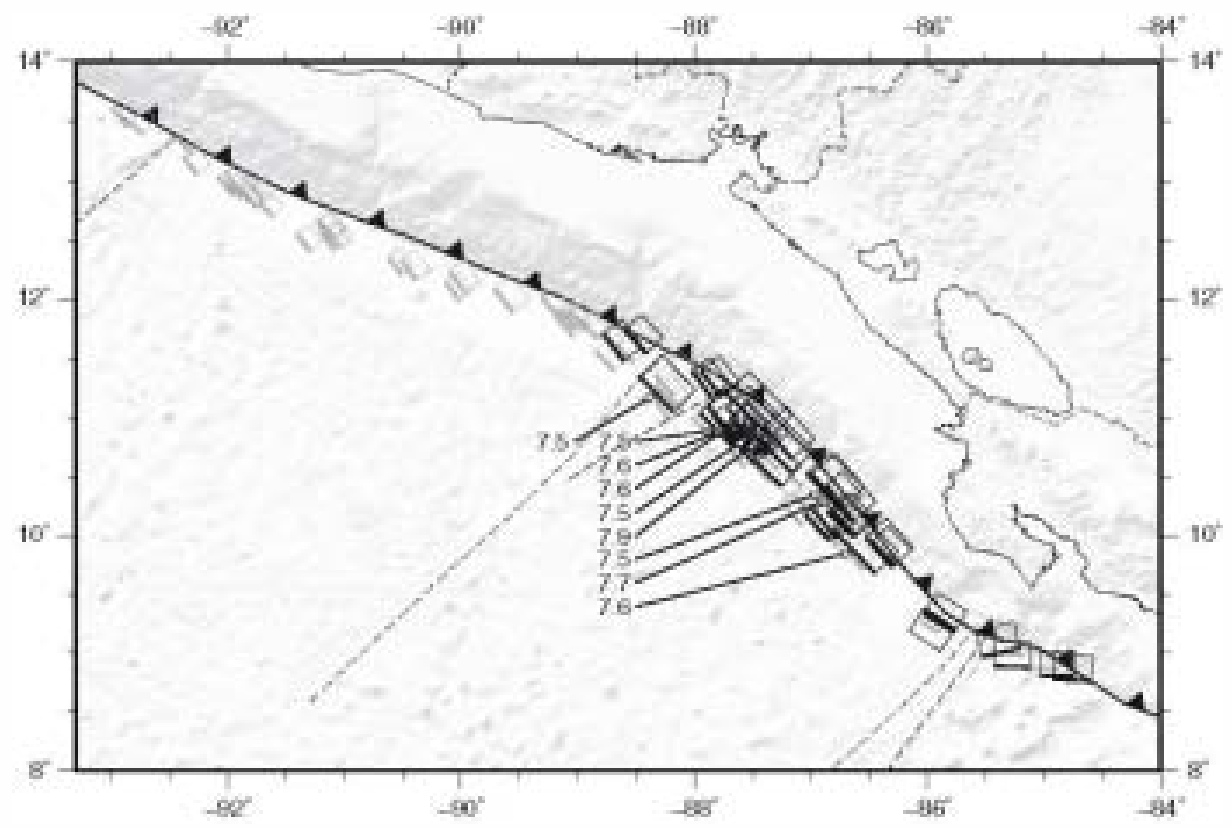

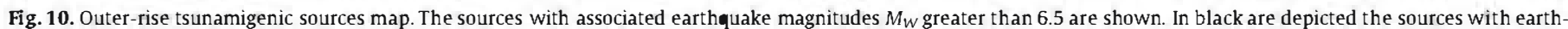

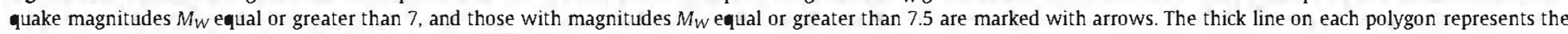
surface trace of the fault as shown in Ranero et al. (2005). 
Table 4

Parameters of the worst case outer rise seismic tsunamigenic source. The geographic location refers to the center of the rectangular rupture.

\begin{tabular}{lllllll}
\hline Iong. & Lat. & $\begin{array}{l}\text { Depth } \\
(\mathrm{km})\end{array}$ & $\begin{array}{l}\text { Iength } \\
(\mathrm{km})\end{array}$ & $\begin{array}{l}\text { Width } \\
(\mathrm{km})\end{array}$ & $\begin{array}{l}\text { Top } \\
(\mathrm{km})\end{array}$ & $\begin{array}{l}\text { Bottom } \\
(\mathrm{km})\end{array}$ \\
\hline-87.443 & 10.812 & 15 & 85 & 42 & 0 & 30 \\
Strike $\left({ }^{\circ}\right)$ & $\operatorname{Dip}\left({ }^{\circ}\right)$ & Rake $\left({ }^{\circ}\right)$ & $\mathrm{Slip}(\mathrm{m})$ & $\mathrm{G}\left(\mathrm{Nm}^{-2}\right)$ & $\mathrm{Mo}(\mathrm{Nm})$ & $M_{w}$ \\
\hline 315 & 45 & -90 & 4.5 & $5.00 \mathrm{E}+010$ & $8.15 \mathrm{E}+020$ & 7.9 \\
\hline
\end{tabular}

La Libertad in El Salvador, but with major damage in the area of Barra de Santiago and Acajutla (Fernández, 2002; Lardé y Larín, 2000) (Fig. 12, point G). The tsunami was triggered by an earthquake with magnitude Ms 7.4 (Pacheco and Sykes, 1992) but could have been due to one of these three main causes: a submarine landslide triggered by the earthquake in one of the continental slope canyons located off this part of the coast; a reverse fault earthquake in the subduction interface but smaller, or deeper, than in 1992; or an outer-rise normal fault earthquake as the modeled in this work. As shown in Fig. 12, the modeled sources OR-5 and OR-6 are capable of generating wave elevations of several meters in the $10 \mathrm{~m}$ depth bathymetric contour in the area affected by the 1902 tsunami. These elevations are sufficient to generate similar or higher run-up heights to those described for the event of 1902 and the extent of the coastal area affected is also similar to that described.

As we have shown in the analysis of seismicity, these outer-rise normal fault earthquakes present a return period for events of magnitudes $7.0 \mathrm{M}_{w}$ or above of 67 years on the Central America Trench. For an event of $M_{w} 7.4$ (equivalent to the earthquake of 1902) the return period is 173 years. Even assuming that the event of 1902 was the last

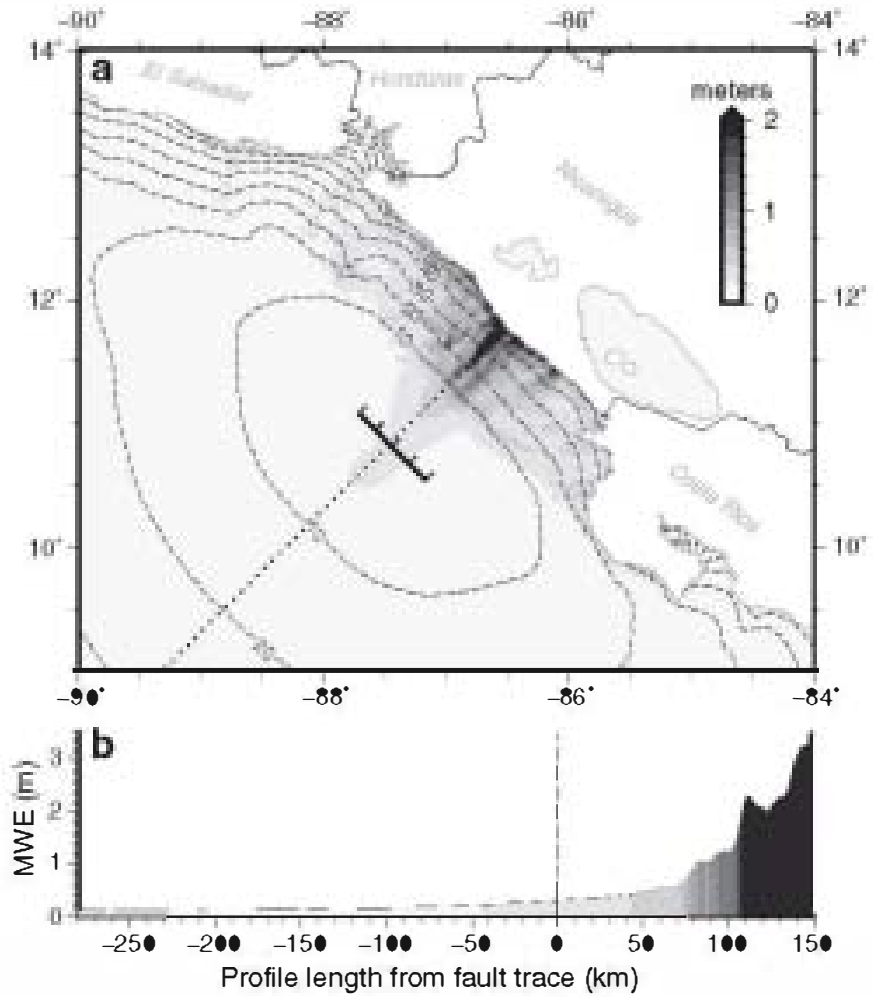

Fig. 11. a) Maximum wave elevation resulted from the propagation numerical model of the parameterized worst-case of the outer-rise faults offshore of Central America Shading shows the wave elevation, dashed contours show the tsunami travel time from the source in minutes, dotted line shows the profile of plot $b$. b) Profile of maximum wave elevation (MWE) across a line perpendicular to the fault trace (dotted line in a). Same gray shading scale of the map a. Dashed line shows the position of the fault trace. damaging earthquake generated by these faults ( 110 years ago), the probability of occurrence of one of these events in the next decades is high based on their return period. Therefore they must be taken into account when conducting studies of tsunami hazard and defining probable future tsunami scenarios.

According to Masson (1991) when the angle between the seafloor-spreading fabric on the incoming plate and the orientation of the trench is less than $30^{\circ}$ the fabric is reactivated during bending and the outer-rise earthquakes are produced in these faults. If the angle is greater than $40^{\circ}$ then new families of fracturing are generated. Ranero et al. (2005) show how this pattern of fracturing in the Central American subduction forms a small angle with the trench, therefore these faults are reactivated, being the potential cause of the outer-rise tsunamigenic earthquakes. Using the empirical relationships developed in this work we obtain a maximum earthquake of $M_{w} 7.9$ based on the dimensions of the faults.

According to Ranero et al. (2005), when the subduction of the thickened oceanic crust of the Cocos Ridge takes place the bend faulting does not occur. If this is true, it is unlikely that a damaging tsunamigenic outer-rise earthquake could take place in the Cocos Ridge vicinity; although it is probable for the northern pacific coast of Central America, from Nicaragua to Guatemala and south of Mexico.

The major faults, and then maybe the greatest potential for generating tsunamis, are located off the coast of Nicaragua. In this area the orientation of the outer-rise normal faults is very similar to the trench trend. The presence of these larger faults could indicate a better orientation of the rupture planes to the local stress tensor in front ofNicaragua. The reactivation of this fracture pattern could then be more efficient where the faults and trench trends are more similar. Another simple explanation would be that as the seafloor fabric subducts oblique to the trench at El Salvador and Guatemala, the large fractures are intersected by the trench and covered by the upper plate. These faults, being subducted partially, would appear shorter than its actual length. If this were the case one might wonder whether even when partially subducted these fractures would be able to break as a continuous segment giving rise to large earthquakes and tsunamis. In this case we could not rule out the occurrence of tsunamis similar to the worstcase defined in this work offshore of El Salvador and Guatemala; and accordingly we modeled this worst case in different locations along the trench.

The capability of these faults to generate ocean-wide tsunamis is low, however, they can produce significant tsunamis locally. Most damage is being produced in front of the fault, with wave elevations reaching several meters off the coast. It is interesting to point out the influence of the morphology of the continental slope in the tsunami damage. When analyzed together, the presence of wave elevation peaks and troughs in certain areas of the coast is evident. Several of these features may be related to the presence of submarine canyons, while others are related to the coastal morphology.

The highest elevations for each modeled source are not necessarily located at the point opposite to its geometric center (Fig. 12), as expected under ideal conditions of regular bathymetry. This is only approximately true for sources located off the coast of Nicaragua, where the continental slope morphology is more regular. In all other sources there is an obvious difference between the center of the source and the highest elevation on the coast. In some cases, there is a trough opposite the central part of the fault (e.g. sources OR-6, OR-8; Fig. 12). From the point of view of the tsunami hazard it would be interesting to characterize in detail the influence of the bathymetry in this area, not just the local shallow bathymetry, but also the regional bathymetry of the continental slope. Their influence on the maximum wave elevation is crucial.

In front of the extent of the 1992 Nicaragua earthquake rupture there are a number of faults capable of generating major earthquakes and tsunamis (Fig. 12). In other parts of the world a relationship between the occurrence of interplate earthquakes and outer-rise 


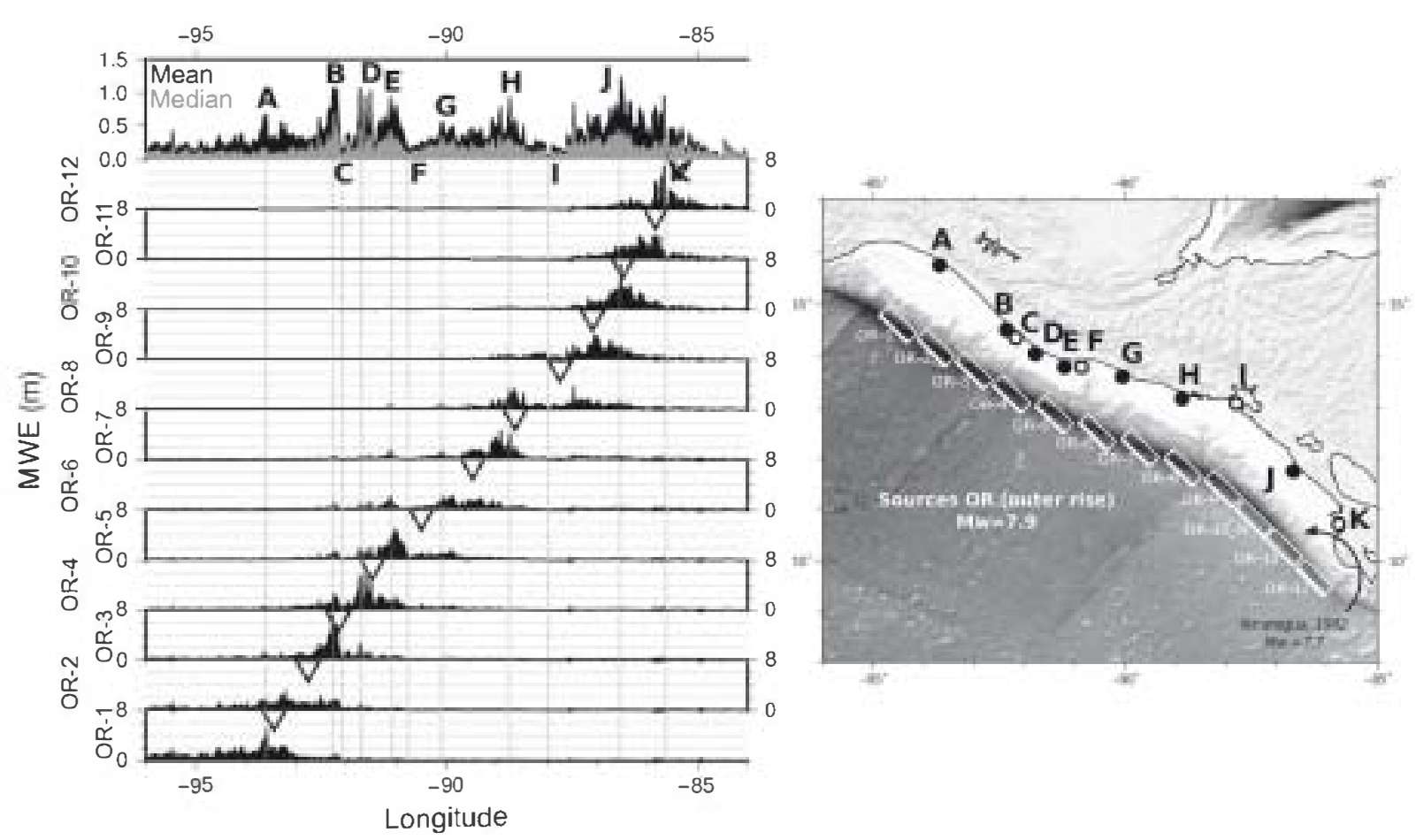

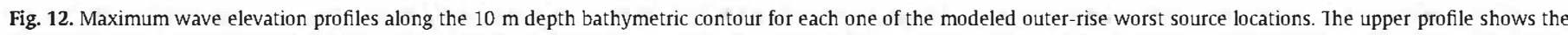

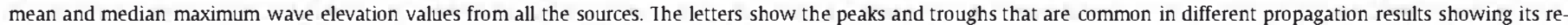

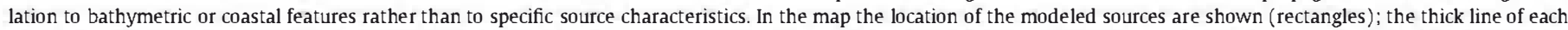

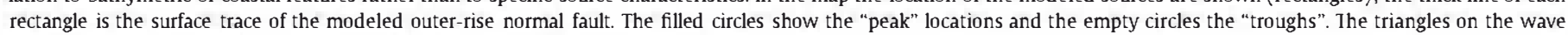
elevation profiles mark the projection of the center of each source on the coast.

earthquakes has been described, especially in coupled subductions (Ammon et al., 2008; Christensen and Ruff, 1988). This occurrence is not only explained by a transfer of slab-pull forces towards the outer-rise in the postseismic phase of the seismic cycle of great interplate earthquakes (Spence, 1987), but also by the occurrence of static stress transfer to the outer-rise faults (Lin and Stein, 2004; Mikumo et al., 2002; Raeesi and Atakan, 2009). It would be worthwhile to analyze the influence of the 1992 Nicaragua event on the outer-rise faults, even 20 years after its occurrence, to make a realistic estimate of the short term threat that these faults pose.

\section{Conclusions}

There is a high frequency of outer-rise normal earthquakes in the Central American subduction compared with the surrounding areas. We should consider these outer-rise faults as probable sources of tsunamis in the future and perhaps as a potential cause of local tsunamis in the past. The most damaging tsunamis in Central America have been produced by local sources.

We have found that the strikes of the faults and of the nodal planes in the focal mechanisms are in the same range. The faults mapped by (Ranero et al., 2005) are then probably responsible for the outer-rise seismicity and the potential cause of tsunamigenic earthquakes.

A maximum magnitude of $M_{W} 7.9$ has been obtained from these faults using an empirical relationship presented in this work. The scarcity of data from this type of events is compensated by the selection of truly representative events of this type of process.

The b-value of the Gutenberg-Richter law for the magnitudes derived from the fault dimensions is on the same range of the one obtained for the normal faulting seismicity. The values of the return period obtained from the outer-rise normal faulting seismicity range between 2 years for a magnitude 5.5 earthquake and 560 years for a magnitude 7.9 earthquake. The return period for a 7.4 magnitude earthquake is 173 years. Even if the tsunami of El Salvador in 1902 had been produced by one of these outer-rise normal faults, considering the return period for a 7.4 earthquake, the probability of occurrence of one of these events in the next decades is high.

The capability of these faults to generate ocean-wide tsunamis is low, however, they can produce significant tsunamis locally. Most damage is produced in front of the fault, with wave elevations reaching several meters at the coast.

Independently on the location of the source along the trench, the maximum wave elevation produced is greater than $2 \mathrm{~m}$, which can generate damaging inundations. Most of the source locations can produce wave elevations greater than $5 \mathrm{~m}$. The affected areas span several hundreds of kilometers along the coast. The presence of wave elevation peaks and troughs in certain areas of the coast is related with submarine canyons and coastal morphology.

The major faults, and therefore the greatest potential for generating tsunamis, are located off the coast of Nicaragua; although we cannot rule out the occurrence of similar tsunamis off shore of El Salvador and Guatemala.

Supplementary data to this article can be found online at http:// dx.doi.org/10.1016/j.tecto.2012.08.014.

\section{Acknowledgments}

This research is part of the project "Tsunami Risk Assessment in El Salvador", funded by the Spanish Agency for International Development Cooperation (AECID). This paper has benefited greatly from the review of Alberto Armigliato, his comments have been key to extend and deepen some aspects of the work. We thank $C$. Ranero and G. Peraldo for their comments and suggestions. The figures have been produced with the software GMT (Wessel and Smith, 1998). This is a contribution from the Ocean \& Coastal Research Group from the Instituto de Hidrálica Ambiental (Universidad de Cantabria) and the Active Tectonics, Paleoseismology and Associated Hazards research group (UCM-910368). 


\section{References}

Abe, K., 1972. Lithospheric normal faulting beneath the Aleutian trench. Physics of the Earth and Planetary Interiors 5, 190-198.

Álvarez Gómez, J.A., 2009. Tectónica Activa y Geodinámica en el Norte de Centroamérica. Ph.D. thesis. Universidad Complutense de Madrid. Madrid.

Álvarez-Gómez, J.A., Meijer, P.T., Martínez-Díaz, J.J., Capote, R., 2008. Constraints from finite element modeling on the active tectonics of northern Central America and the Middle America Trench. Tectonics 27 http://dx.doi.org/10.1029/2007TC002162.

Ammon, C. J., Kanamori, H., Iay, T., 2008. A great earthquake doublet and seismic stress transfer cycle in the central Kuril islands. Nature 451,561-565. http://dx.doi.org/ 10.1038 /nature06521

Andrews, D.J., 1980. A stochastic fault model 1. Static case. Journal of Geophysical Research 85, 3867-3877.

Baptista, A.M., Priest, G.R., Murty, T.S., 1993. Field sırvey of the 1992 Nicaragua tsunami. Marine Geodesy 16, 169-203. http://dx.doi.org/10.1080/15210609309379687.

Beavan, J., Wang X., Holden, C., Wilson, K., Power, W., Prasetya, G., Bevis, M., Kautoke, R. 2010. Near-simultaneous great earthquakes at Tongan megathrust and outer rise in September 2009. Nature 466, 959-963 http://dx.doi.org/10.1038/nature09292.

Beck, S.L., Christensen, D.H., 1991. Rupture process of the February 4, 1965, Rat Islands earthquake. Journal of Geophysical Research 96, 2205-2221.

Burbach, G.V, Frohlich, C., Pennington, W.D., Matumoto, T., 1984. Seismicity and tectonics of the subducted Cocos plate. Joumal of Geophysical Research 89, 7719-7735.

Chapple, W.M., Forsyth, D.W., 1979. Earthquakes and bending of plates at trenches. Journal of Geophysical Research 84, 6729-6749.

Christensen, D.H., Ruff, L.J., 1988. Seismic coupling and outer rise earthquakes. Journal of Geophysical Research 93, 13241-13444.

Conrad, C.P., Bilek, S., Lithgow-Bertelloni, C., 2004. Great earthquakes and slab pull: interaction between seismic coupling and plate-slab coupling. Earth and Planetary Science Letters 218, 109-122.

Dowrick, D.J., Rhoades, D.A., 2004. Relations between earthquake magnitude and fault rupture dimensions: how regionally variable are they? Bulletin of the Seismological Society of America 94, 776-788. http://dx.doi.org/10.1785/0120030151.

Ekström, G., Nettles, M., Dziewoński, A., 2012. The global CMT project 2004-2010: centroid-moment tensors for 13,017 earthquakes. Physics of the Earth and Planetary Interiors 200-201,1-9.

Fernández, M., 2002. Daños, efectos y amenaza de tsunamis en América Central Revista Geológica de América Central 26, 71-83.

Fernández, M., Alvarado-Delgado, G., 2005. Tsunamis and tsunami preparedness in Costa Rica, Central America. ISET Journal of Earthquake Technology 42, 203-212.

Fernández, M., Molina, E., Havskov, J., Atakan, K., 2000. Tsunamis and tsunami hazards in Central America. Natural Hazards 22, 91-116.

Fernández, M., Ortiz-Figueroa, M., Mora, R., 2004. Tsunami hazards in El Salvador. Geological Society of America Special Paper 375, 435-444.

Fromm, R., Alvarado, P., Beck, S., Zandt, G., 2006. The April 9, 2001 Juan Fernández Ridge ( $\left.\mathrm{M}_{W} 6.7\right)$ tensional outer-rise earthquake and its aftershock sequence. Joumal of Seismology 10, 163-170.

Fujii, Y., Satake, K., 2008. Tsunami sources of the November 2006 and January 2007 Great Kuril earthquakes. Bulletin of the Seismological Society of America 98, 1559-1571.

Gasperini, P., Vannucci, G., 2003. FPSPACK: a package of FORTRAN subroutines to manage earthquake focal mechanism data. Computers \& Geosciences 29, 893-901

GEBCO, 2008. The GEBCO_08 Grid, version 20081212. http:/Mrww.gebco.net.

George, D.L., 2008. Augmented Riemann solvers for the shallow water equations over variable topography with steady states and inundation. Journal of Computational Physics 227, 3089-3113.

Gusman, A.R., Tanioka, Y., Matsumoto, H., Iwasaki, S.L, 2009. Analysis of the tsunami generated by the Great 1977 Sumba earthquake that occurred in Indonesia. Bulletin of the Seismological Society of America 99, 2169-2179. http://dxdoi.org/10.1785/ 0120080324.

Guzmán-Speziale, M., Gómez-González,J.M., 2006. Seismic strain rate along the Middle America Trench reveals significant differences between Cocos-North America and Cocos-Caribbean convergence. Geophysical Journal International 166, 179-185.

Hanks, T.C., 1979. b Values and $\omega^{-\gamma}$ seismic source models: implications for tectonic stress variations along active crustal fault zones and the estimation of highfrequency strong ground motion. Journal of Geophysical Research 84, 2235-2242.

Ide, S., Imamura, F., Yoshida, Y., Abe, K., 1993. Source characteristics of the Nicaraguan tsunami earthquake of September 2, 1992. Geophysical Research Letters 20, 863-866.

Imamura, F., Shuto, N., Ide, S., Yoshida, Y., Abe, K., 1993. Estimate of the tsunami source of the 1992 Nicaraguan earthquake from tsunami data. Geophysical Research Letters $20,1515-1518$

Kanamori, H., 1971. Seismological evidence for a lithospheric normal faulting - the Sanriku earthquake of 1933. Physics of The Earth and Planetary Interiors 4 $289-300$

Kirby, S.H., Hino, R, Umino, N., Gamage, S., Hasegawa, A., Nishizawa, A., Engdahl, E.R. Bergman, E., 2008. The 75th anniversary of the great Sanriku-oki, Japan earthquake of March 2nd, 1933: new observations and new insights into the largest recorded outer-rise earthquake. AGU Fall Meeting Abstracts, A5 +

Kreemer, C., Holt, W.E., Haines, A. J., 2003. An integrated global model of present-day plate motions and plate boundary deformation. Geophysical Journal International $154,8-34$

Lardé y Larín, J., 2000. El Salvador: Inundaciones e incendios, Erupciones y terremotos, 2nd edition. Editorial DPI, San Salvador, El Salvador. earthquakes. Geophysical Journal International 172, 240-251.

Lin, J., Stein, R.S., 2004. Stress triggering in thrust and subduction earthquakes and stress interaction between the southern San Andreas and nearby thrust and strike-slip faults. Journal of Geophysical Research 109, 1-19.

Liu, P.L.F., Cho, Y.S., Briggs, M.J., Kanoglu, U., Synolakis, C.E, 1995. Runup of solitary waves on a circular island. Journal of Fluid Mechanics 302, 259-285.

Lynnes, C.S., Lay, T., 1988. Source process of the great 1977 Sumba earthquake. Journal of Geophysical Research 93, 13407-13420.

Lyon-Caen, H., Barrier, E., Iasserre, C., Franco, A., Arzu, I., Chiquin, L., Chiquin, M. Duquesnoy, T., Flores, O., Galicia, O., Luna, J., Molina, E., Porras, O., Requena, J. Robles, V., Romero, J., Wolf, R., 2006. Kinematics of the North AmericanCaribbean-Cocos plates in Central America from new GPS measurements across the Polochic-Motagua fault system. Geophysical Research Letters 33, -19309.

Masson, D.G., 1991. Fault patterns at outer trench walls. Marine Geophysical Research 13, 209-225

Mikumo, T., Yagi, Y., Singh, S.K., Santoyo, M.A., 2002. Coseismic and postseismic stress changes in a subducting plate: possible stress interactions between large interplate thrust and intraplate normal-faulting earthquakes. Journal of Geophysical Research $107,2023$.

Okada, Y, 1985. Surface deformation due to shear and tensile faults in a half-space. Bulletin of the Seismological Society of America 75, 1135-1154.

Olabarrieta, M., Medina, R., Gonzalez, M., Otero, L., 2011. C3: a finite volume-finite difference hybrid model for tsunami propagation and runup. Computers \& Geosciences37, 1003-1014.

Olsson, R., 1999. An estimation of the maximum b-value in the Gutenberg-Richter relation. Journal of Geodynamics 27, 547-552

Pacheco, J.F., Sykes, L.R., 1992. Seismic moment catalog of large shallow earthquakes, 1900 to 1989. Bulletin of the Seismological Society of America 82, 1306-1349.

Pacheco, J.F., Sykes, L.R., Scholz, C.H., 1993. Nature of seismic coupling along simple plate boundaries of the subduction type. Journal of Geophysical Research 98 , $14133-14159$.

Pelayo, A.M., Wiens, D.A., 1992. Tsunami earthquakes: slow thrust-faulting events in the accretionary wedge. Journal of Geophysical Research 97, 15321-15337.

Raeesi, M., Atakan, K., 2009. On the deformation cycle of a strongly coupled plate interface: the triple earthquakes of 16 March 1963, 15 November 2006, and 13 January 2007 along the Kurile subduction zone. Journal of Geophysical Research 114, B10301.

Ranero, C.R., Morgan, J.P., McIntosh, K., Reichert, C, 2003. Bending-related faulting and mantle serpentinization at the Middle America trench. Nature 425, 367-373.

Ranero, C.R., Villaseñor, A., Morgan, J.P., Weinrebe, W., 2005. Relationship between bend-faulting at trenches and intermediate-depth seismicity. Geochemistry, Geophysics, Geosystems 6, -12002.

Satake, K., 1994. Mechanism of the 1992 Nicaragua tsunami earthquake. Geophysical Research Letters 21, 2519-2522.

Satake, K., Yoshida, Y., Abe, K., 1992. Tsunami from the Mariana earthquake of April 5 1990: its abnormal propagation and implications for tsunami potential from outer rise earthquakes. Geophysical Research Letters 19, 301-304.

Satake, K., Bourgeois, J., Abe, K., Abe, K., Tsuji, Y., Imamura, F., Lio, Y., Katao, H., Noguera, E., Estrada, F., 1993. Tsunami field survey of the 1992 Nicaragua earthquake. EOS Transactions of the American Geophysical Union 74, 145-157.

Siebert, L., Simkin, T., 2002. Volcanoes of the world: an illustrated catalog of Holocene volcanoes and their eruptions. Smithsonian Institution, Global Volcanism Program Digital Information Series, GVP-3. http:/Www.volcano.si.edu/world/

Spence, W., 1986. The 1977 Sumba earthquake series: evidence for slab pull force acting at a subduction zone. Journal of Geophysical Research 91, 7225-7239.

Spence, $W$., 1987. Slab pull and the seismotectonics of subducting lithosphere. Reviews of Geophysics 25, 55-69.

Stirling, M., Rhoades, D., Berryman, K., 2002. Comparison of earthquake scaling relations derived from data of the instrumental and preinstrumental era. Bulletin of the Seismological Society of America 92, 812-830. http://dx.doi.org/10.1785/ 0120000221.

Strasser, F.O., Arango, M.C., Bommer, J.J., 2010. Scaling of the source dimensions of interface and intraslab subduction-zone earthquakes with moment magnitude. Seismological Research letters 81, 941-950. http://dx.doi.org/10.1785/gssrI.81.6.941.

Tanioka, Y., Satake, K., 1996. Fault parameters of the 1896 Sanriku tsunami earthquake estimated from tsunami numerical modeling. Geophysical Research Letters 23, $1549-1552$.

Tanioka, Y., Hasegawa, Y., Kuwayama, T., 2008. Tsunami waveform analyses of the 2006 underthrust and 2007 outer-rise Kurile earthquakes. Advances in Geosciences 14, $129-134$.

Velasco, A.A., Ammon, C.J., Lay, T., Zhang, J., 1994. Imaging a slow bilateral rupture with broad band seismic waves; the September 2, 1992 Nicaraguan tsunami earthquake. Geophysical Research Letters 21, 2629-2632.

Wells, D.L., Coppersmith, K.J., 1994. New empirical relationships among magnitude, rupture length, rupture width, rupture area, and surface displacement. Bulletin of the Seismological Society of America 84, 974-1002.

Wessel, P., Smith, W.H.F., 1998. New improved version of generic mapping tools released. EOS Transactions of the American Geophysical Union 79, 579.

Wiemer, S., 2001. A software package to analyze seismicity: ZMAP. Seismological Research Letters 72, 373-382.

Yoshida, Y., Satake, K., Abe, K., 1992. The large normal-faulting Mariana earthquake of April 5, 1990 in uncoupled subduction zone. Geophysical Research Letters 19, $297-300$. 